\title{
LEVANTAMENTO SOBRE A APLICAÇÃO DA PALAVRA “DESIGN" EM PRODUTOS E SERVIÇOS NA CIDADE DE SÃO LUÍS (MA)
}

Raimundo Lopes Diniz

Programa de Pós-Graduação em Design

(UFMA)

rl.diniz@ufma.br

Moisaniel Pimentel Arruda Filho

Graduando em Design (UFMA)

moisa_filho@hotmail.com
Maíza Luíza Silva Araújo

Graduanda em Design (UFMA)

araujo.maizals@gmail.com

Rubênio dos Santos Barros

Graduando em Design (UFMA)

rubeniobarros@gmail.com

Resumo: O presente artigo tem como objetivo investigar as aplicações da palavra design nos estabelecimentos comerciais como uma proposta de promoção de produtos e/ou serviços em de São Luís (MA). Tal foi, abordado a complexidade e o caráter polissêmico que a palavra design dispõe, de modo a compreender como essas definições e conceitos são empregados pela população ludovicense. Realizaram-se fotográficos do emprego da palavra em diversas mídias, como outdoors, panfletos, banners, cartazes, cartões de visitas, instagram, placas e fachadas, com o intuito de divulgação de serviços e produtos. Os resultados foram organizados e analisados de acordo com a classificação polissêmica da palavra "Design" proposta por van der Linden et al (2014). No geral, os resultados apontaram que a compreensibilidade do conceito da palavra "design", está amplamente associado a valores estéticos e comerciais, sendo assim, difundido e apreendido parcialmente, distanciando-se da essência do design.

Palavras-chave: Design; Conceito; Polissêmico.

Abstract: This paper aims to investigate the applications of the word design in commercial establishments as proposal promotion of products and services from São Luís (MA). For this, it addressed the complexity and ambiguous character that the word design have in order to understand how these definitions and concepts are employed by ludovicense population. Photographic records were held in the city about the use of the word in various media such as billboards, brochures, banners, posters, business cards, instagram, plates and frontages for the purpose of dissemination of services and products. The results were arranged and analyzed according to the polysemic classification of the word design proposed by van der Linden et al (2014). Overall, the results showed that the comprehensibility of the concept of the word "design" is widely associated with aesthetic and commercial values, and so, widespread and seized part, moving away from the essence of the design. 
Keywords: Design; Concept; Polysemy.

\section{INTRODUÇÃO}

É cada vez maior a disseminação do design no Brasil, em que se percebe o "design" como um motor de impacto em diversas áreas, devido ao seu caráter multidisciplinar e capaz de alcançar todas as esferas da sociedade. Desta forma, o contato com a palavra "design" ocorre constantemente, fazendo parte de um novo vocabulário (AZEVEDO, 1998).

Segundo Moura (2003) o termo ou palavra design originalmente chegou no Brasil nos anos 50 como desenho industrial, somente a partir dos anos 80 a utilização da nomenclatura em inglês foi aplicada. Entretanto, os profissionais, pesquisadores e estudiosos da área almejam ainda por definir de forma sólida o que é o design, pois os seus significados têm implicado na massificação do termo e utilizações impróprias da palavra, que segundo Cardoso (2013, p. 234) "tende ao infinito - ou seja, a dialogar em algum nível com quase todos os outros campos de conhecimentos [...] o design deve ser concebido como um campo ampliado que se abre para diversas outras áreas, algumas mais próximas, outras mais distantes". Por se tratar de uma área multidisciplinar e holística, acaba por dar evasão, contribuindo com os equívocos encontrados e por ser um campo de diversas possibilidades, acaba gerando usos mais folclóricos como "hair designer" para cabeleireiros e "nail designer" para manicure (CARDOSO, 2013).

Além disso, segundo Löbach (2001), existe uma divergência entre os conceitos aprendidos pelos leigos sobre o design, estes decoram seu entorno de modo intuitivo difundidos pela mídia. Entendendo assim somente os aspectos parciais da essência do design. Bonsiepe (2012) corrobora ao citar que a explosão do termo nas mídias levou a perda do seu significado original, levando a opinião pública o entendimento efêmero e até mesmo supérfluo do que é o design. Ocasionando, assim, um véu de dúvidas acerca do termo, relacionando-o intrinsecamente com a experiência estética e menos com o domínio discursivo.

Em São Luís, não há um consenso na disseminação do conceito de Design, isto pode ser observado através do número de cursos oferecidos na região. Como aponta o relatório "O design no Brasil" levantado pelo Sebrae em 2014, na cidade, há apenas dois cursos de graduação em uma instituição particular e em uma instituição federal. Apenas uma especialização, sendo esta na área de Interiores. Enquanto cursos técnicos, oferecem dois: design de móveis e design de interiores.

Desta forma, o presente artigo aborda um parecer do emprego da palavra design, com base na classificação proposta por van der Linden et al (2014) em São Luís (MA), observou-se como o termo "design" foi utilizado na promoção de empreendimentos, cursos, produtos e serviços, com a intenção de compreender como a população se apropriava e divulgava o que supostamente entendiam por design. 


\section{O TERMO “DESIGN"}

De acordo com Bomfim "a expressão design surgiu no século XVII, na Inglaterra, como tradução do termo italiano 'disegno', mas somente com o progresso da produção industrial e com a criação das 'Schools of Design' a expressão passou a caracterizar uma atividade específica no processo de configuração de objetos de uso e sistemas de informação" (BOMFIM, 2002, p 118).

Segundo os dicionários Escolar Latino-Português (1962) e Houaiss (2009) o termo design provém do verbo latino designare (-o,-as,-avi,-atum), o qual expressa marcar, desenhar, indicar, designar, traçar, representar, ordenar, dispor e regular. Também significa: "inventar alguma coisa", "simular", "desenhar", "dar forma" e "ter desenhos em alguma coisa" (MOURA, 2003 apud FLUSSER, 1999), além do mais, é interpretado como uma ação realizada pelas pessoas, indicando uma atividade. Contudo, na língua inglesa, o termo design tanto é verbo como é substantivo, e para esta última, a palavra significa: desígnio, intenção e plano. Moura (2003) apud Flusser (1999) completa com "propósito", "objetivo", "esquema", "motivo", "enredo" e "estrutura básica", estes estão ligados a "esperteza" e a "ilusão".

O seu significado, porém, vai mais além, acrescentando-se definições, como: projeto, configuração, modelo, esboço, desenho, solução, além de denotar representação gráfica, nome de produtos, objetos e atividades profissionais (VAN DER LINDEN et al, 2014). Para este último, portanto, não se deve esquecer que há uma variante específica do termo para sua utilização, o "designer". Moura (2003, p. 88) o define como: "indivíduo que planeja ou concebe um projeto ou modelo, aquele que cria um produto em novo estilo ou apresentação e de modo restrito pode ser tratado como Desenhista-industrial, Desenhista-de-produto, Programador visual, especialista que trabalha com design gráfico."

No Brasil, a nomenclatura surgiu no final dos anos 80 e a medida que os meios tecnológicos eram difundidos, intensificou-se a utilização e a proliferação do termo. Moura (2003) aponta, por exemplo, a expressão "digital design" que surge junto com as tecnologias dos softwares, neste caso o CAD (Computer Aided Design) ou projetos assistidos por computador.

Todavia, no âmbito popular, o termo "design" está associado a percepção de beleza, sendo assim um dos conceitos mais difundidos e apreendidos pelo público (LANDIM, 2010). Por isso, é extremamente comum nos depararmos com frases "Eu gosto do design", onde a noção de estética pode ser notada facilmente (VAN DER LINDEN et al, 2014 apud FORTY, 2007), da mesma maneira como o design é percebido em alguns segmentos industriais, em que ainda é persistente o seu posicionamento como um fator de embelezamento do produto previamente planejado (GODOY et al, 2012).

Além disso, a palavra "design" encontra-se aplicada como estratégia na promoção de produtos e serviços, como exemplificado por Moura (2003) em que cabelereiros, perfumistas, floristas e confeiteiros intitulam as suas atividades como design. E completa, que a maioria das práticas comerciais que envolvem criação ou produção direta ou indiretamente, facilmente são associados ao design. Cardoso (2013) contribui 
ao relatar que a utilização da titulação "designer", como atuante profissional, também é aplicada para denominar crescentes atividades comerciais.

\section{MÉTODOS E TÉCNICAS}

O estudo teve como natureza a pesquisa descritiva, na qual há o registro e descrição dos fatos observados, sem interferir nos mesmos. Visam a descrever as características de determinados nichos ou fenômenos, ou as interações entre estas variáveis (PRODANOV e FREITAS, 2013). Dessa forma, a presente pesquisa realizou levantamentos de registros fotográficos da utilização da palavra Design em produtos e serviços na cidade de São Luís (MA). Por meio de câmeras de smartphones compartilharam-se em um grupo composto por 14 pessoas, no aplicativo WhatsApp Messenger, 54 fotos da aplicação do termo, estas oriundas de mídias como: panfleto, outdoors, banners, cartazes, cartões de visitas, placas e fachadas, no período entre outubro de 2015 e maio de 2016. Todas as aplicações registradas foram analisadas, levando em consideração, também, o mapeamento dos bairros. Para isso, utilizou-se como referência o livro do projeto "São Luís: uma leitura da cidade", realizado pelo Instituto de Pesquisa e Planificação da Cidade em 2006. $O$ arquivo contém índices do rendimento nominal mensal de cada bairro e foram utilizados para analisar se existem correlações entre o emprego da palavra "design" nos empreendimentos e o seu entorno.

Com o intuito de analisar a utilização da palavra, as imagens foram organizadas na Planilha Microsoft Excel (2010), para posteriormente classificá-las de acordo com a proposta de van der Linden et al (2014), em que, aceitando o caráter complexo e multifacetado acerca do design, elaborou uma classificação polissêmica da palavra quanto ao seu uso e contexto. (Quadro 1)

Quadro 1: Classificação da palavra design por van der Linden et al (2014).

Adaptado pelos autores.

\begin{tabular}{|c|c|c|c|c|}
\hline $\begin{array}{l}\text { Substantivo } \\
\text { abstrato }\end{array}$ & Verbo & Representação & Artefato & $\begin{array}{l}\text { Resolução de } \\
\text { problemas }\end{array}$ \\
\hline $\begin{array}{l}\text { Tem alusão a plano, } \\
\text { desígnio e intenção, } \\
\text { na qual expressa } \\
\text { projeto no sentido } \\
\text { de desejo ou a ideia } \\
\text { de produzir ou } \\
\text { realizar algo. }\end{array}$ & $\begin{array}{l}\text { Significa desenhar, } \\
\text { indicar, designar, } \\
\text { simular, dispor, } \\
\text { representar, dar } \\
\text { forma, ordenar, etc. } \\
\text { É um conjunto de } \\
\text { ações que resultam } \\
\text { em um produto } \\
\text { final. }\end{array}$ & $\begin{array}{l}\text { Esboço, desenho, } \\
\text { projeto, um modelo } \\
\text { de representação } \\
\text { gráfica. Consiste na } \\
\text { forma de transpor a } \\
\text { ideia (o imaterial, } \\
\text { abstrato) ao } \\
\text { concreto, } \\
\text { transformando-o } \\
\text { em artefato. }\end{array}$ & $\begin{array}{l}\text { É o próprio produto } \\
\text { da concepção de um } \\
\text { projeto e o } \\
\text { resultado pode ser } \\
\text { tanto bidimensional } \\
\text { como } \\
\text { tridimensional. }\end{array}$ & $\begin{array}{l}\text { É a forma como o } \\
\text { designer utiliza } \\
\text { métodos e } \\
\text { técnicas para } \\
\text { atingir } \\
\text { determinados } \\
\text { objetivos. }\end{array}$ \\
\hline $\begin{array}{l}\text { Aparência de um } \\
\text { produto }\end{array}$ & $\begin{array}{l}\text { Atividade } \\
\text { profissional }\end{array}$ & Disciplina & Pesquisa & Designs \\
\hline $\begin{array}{l}\text { Relacionado às } \\
\text { configurações } \\
\text { estéticas do } \\
\text { produto. }\end{array}$ & $\begin{array}{l}\text { O atuante e } \\
\text { profissional do } \\
\text { design. }\end{array}$ & $\begin{array}{l}\text { Relacionado ao } \\
\text { corpo de } \\
\text { conhecimento, } \\
\text { conteúdos e bases } \\
\text { de pesquisa para o } \\
\text { curso de Design. }\end{array}$ & $\begin{array}{l}\text { Investigação } \\
\text { sistemática cujo } \\
\text { objetivo é } \\
\text { conhecimento ou a } \\
\text { materialização de } \\
\text { coisas e sistemas } \\
\text { feitos pelo homem. }\end{array}$ & $\begin{array}{l}\text { Reflexo da } \\
\text { polissemia e o } \\
\text { caráter complexo } \\
\text { da palavra design. }\end{array}$ \\
\hline
\end{tabular}


Contudo, para a pesquisa, a classificação Design enquanto verbo, foi excluída enquanto parâmetro de análise, pois design ao ser utilizado como verbo na língua portuguesa necessita do uso de uma palavra similar como designar, indicar ou representar. Ou seja, somente assim, ela consegue indicar a ação, como todo verbo propõe. Portanto, como a pesquisa foca na palavra Design em si e não em suas variações, ela não pôde ser localizada visualmente, sendo assim, excluída.

As classificações enquanto à representação, artefato, resolução de problemas, pesquisa e designs não foram detectadas, esta ocorrência deve-se ao fato de que a palavra design, nestes casos, são frequentemente mais utilizadas na comunicação verbal, assim como também são dificilmente vinculadas as atividades comerciais.

\section{RESULTADOS E DISCUSSÕES}

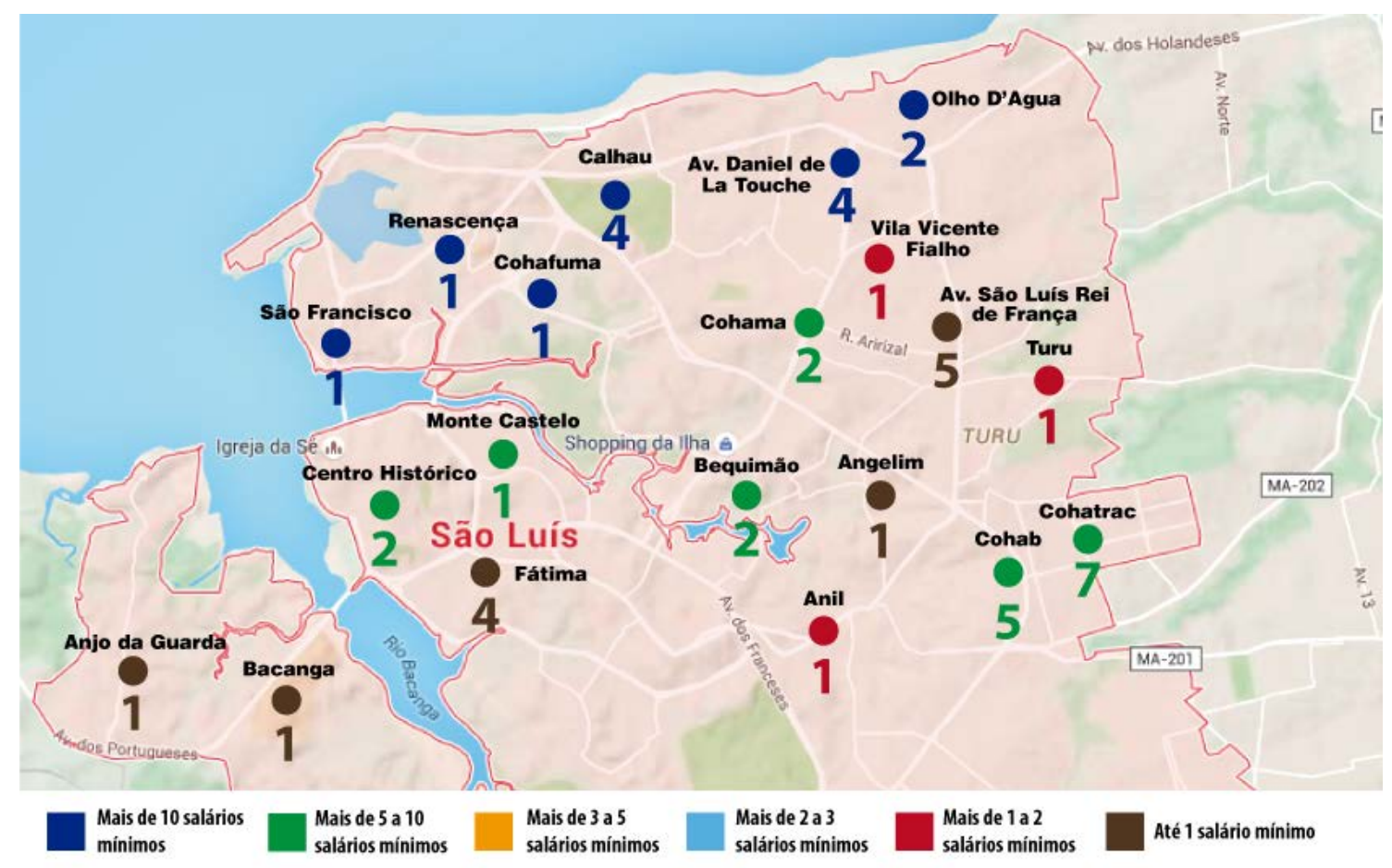

Figura 1: Mapeamento da palavra design registrada em São Luís (MA) através do rendimento nominal mensal de cada bairro.

Elaborado pelos autores, com base na pesquisa realizada.

De acordo com a figura 1, os bairros com maiores índices de rendas mensais, com mais de 10 salários mínimos, apresentam $28 \%$ do total da amostra coletada, sendo em sua maioria amostras referentes aos grupos dos substantivos abstratos e atividades profissionais de acordo com a classificação de van der Linden et al (2014). As áreas que possuíam indivíduos com renda entre 5 a 10 salários mínimos, houve um alcance de $40 \%$, sendo está o grupo de renda com maior incidência da amostra. As duas menores taxas de renda, os grupos de 1 e entre 1 e 2 salários correspondem, respectivamente, $26 \%$ e $6 \%$ do total. Nestas áreas as análises indicam a incidência maior de substantivo abstrato, como especificado na tabela abaixo. 
Tabela 1: Apresentação do rendimento nominal mensal de cada bairro, junto a classificação da palavra Design proposta por van der Linden et al (2014).

Elaborado pelos autores, com base na pesquisa realizada.

RENDA

\begin{tabular}{|c|c|c|c|c|}
\hline & Substantivo Abstrato & $\begin{array}{l}\text { Atividade } \\
\text { Profissional }\end{array}$ & Aparência & Disciplina \\
\hline + De 10 salários mínimos & $5(38 \%)$ & $6(46 \%)$ & $1(8 \%)$ & $1(8 \%)$ \\
\hline $\begin{array}{c}\text { + De } 5 \text { a } 10 \text { salários } \\
\text { mínimos }\end{array}$ & $6(32 \%)$ & $7(37 \%)$ & $2(10 \%)$ & $4(21 \%)$ \\
\hline $\begin{array}{c}\text { + De } 1 \text { a } 2 \text { salários } \\
\text { mínimos }\end{array}$ & $3(100 \%)$ & - & - & - \\
\hline Até 1 salário mínimo & $6(50 \%)$ & $5(42 \%)$ & $1(8 \%)$ & - \\
\hline
\end{tabular}

Independente da renda nominal mensal dos bairros, o uso do termo "design" classificada como substantivo abstrato e atividade profissional, foi utilizada tanto em zonas de alta renda, como as de baixa renda. Moura (2003) exemplifica ao constatar que o uso deturpado da palavra deixou de ser algo requintado, ou utilizado por elites e que atualmente o design passou a ser empregado por todas as classes. Por outro lado, design como disciplina não foram encontrados em áreas de renda inferior a 2 salários mínimos. Além disso, design como aparência foi empregado por indivíduos de classes altas e baixa, principalmente para supostamente designar qualidades de seus serviços e produtos. (Tabela 1)

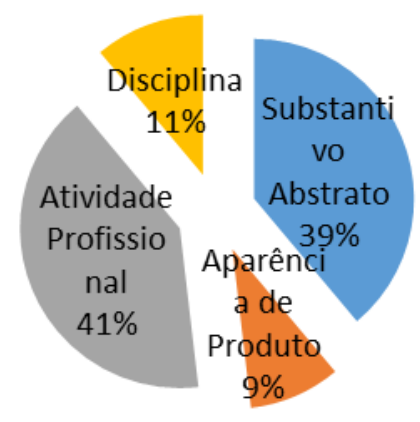

Figura 2: Frequência da classificação do uso da palavra design em São Luís.

Elaborado pelos autores, com base na pesquisa realizada.

De modo geral, dos registros fotográficos coletados em São Luís, $41 \%$ referem-se a design como atividade profissional, contendo 22 imagens. De todas, 19 (86,36\%) estavam sendo utilizadas para "designer de sobrancelhas" (Isso sem contar com 2 substantivos abstratos, o "Salão Gloria Design" e a "Sobrancelhas Design" que também denotam este ramo). Outros dois encontram-se aplicados no instagram, oferecendo serviços de "design de convites" e "cake design". Essa apropriação da palavra design para promover marcas e serviços é explicada por Landim (2008), que posiciona o design como uma força que agrega valor à imagem. A sua vasta utilização acaba gerando equívocos e deturpações, o que leva a exposição do design em serviços como o "Design de Sobrancelhas", "Design de Convites" e o "Design de Bolos". Ressalta-se 
que para esta classificação, obteve-se apenas um registro do uso da palavra design para o profissional graduado da área.

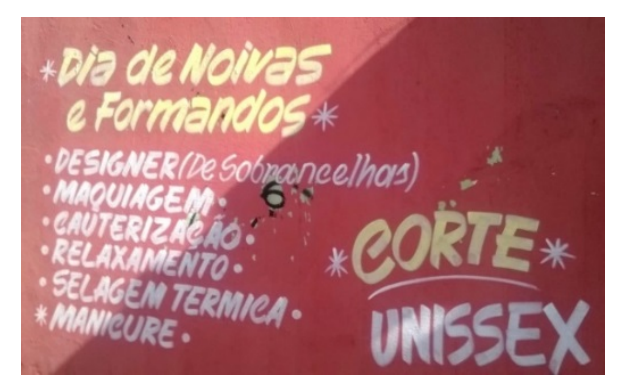

Figura 3: Exemplo do emprego da palavra design para o serviço de design de sobrancelhas.

Elaborado pelo autor, com base na pesquisa realizada.

Design enquanto substantivo abstrato, a segunda classificação com maior frequência, obteve 39\% dos registros. Portanto, o termo "design", aqui, foi levado a outro patamar, visto que o seu uso popular e coloquial distorce os conceitos propostos por van der Linden et al (2014) em que, em São Luís, obtiveram-se exemplos concernentes a títulos dados a empreendimentos. Ao todo, 85,71\% da classe dos substantivos foram utilizadas com essa intenção. Estas, contudo, foram empregadas para representar diversos ramos de empresas, tais como: "Som Design", que representa uma oficina mecânica; "Gloria Design", que nomeia um salão de beleza; "Designcia" e "MídiaDesign", títulos utilizados em gráficas; "Sensação design" e "Pratice Design" para empresas que trabalham com móveis planejados, entre outros (Figura 4). Estes resultados podem ser considerados como o que relata Landim (2008), a qual descreve que desde os anos 80 do século XX, o uso da palavra "design" vêm sido apropriado pela mídia em massa e a publicidade para agregar valor aos produtos e chamar a atenção dos consumidores. Bonsiepe (2012) contribui relatando que o design é equivocadamente visto como um agregador de valor, portanto afirma que ele vai mais além, pois o mesmo é intrínseco a cada objeto, sendo parte de sua essência. Fascioni (2014) apud Nussbaun (2002) completa que estes modelos de empreendimentos fazem uso somente de $5 \%$ do design, deixando de usufruir $95 \%$ de suas estratégias de gestão.

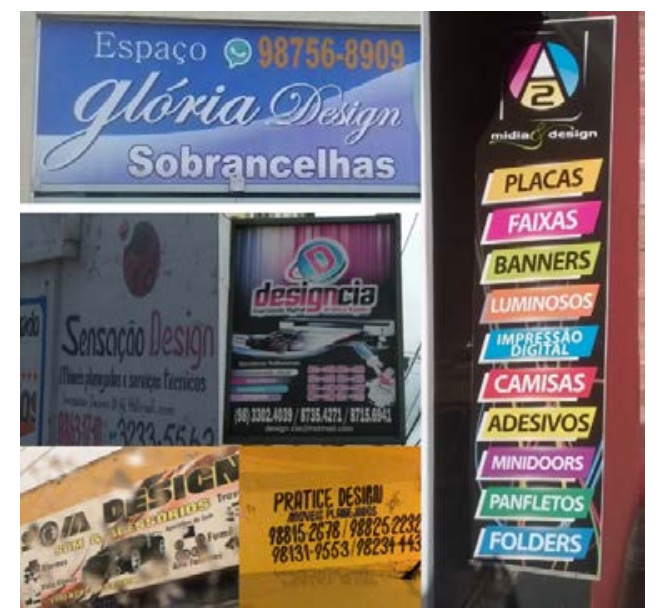

Figura 4: Exemplos de empreendimentos de diferentes ramos utilizando a palavra "design" em seus títulos. Elaborado pelos autores, com base na pesquisa realizada. 
A aplicação de $11 \%$ dos registros remete design à disciplina e todas possuem vínculos com cursos técnicos. Com exceção de um, que foi coletado do facebook, todos foram coletados em bairros de IDHM médio. No exemplo da figura 4, o banner, com o uso da palavra, comunica alguns dos seus cursos oferecidos, como "web design" e "design gráfico".

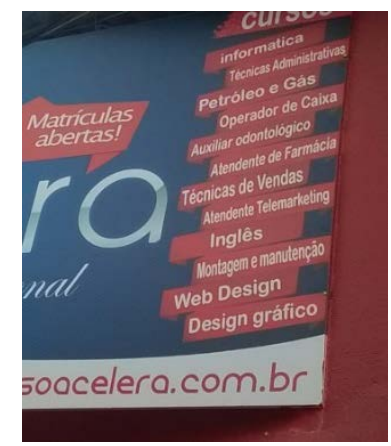

Figura 5: Banner comunicando os cursos técnicos para matrícula.

Elaborado pelos autores, com base na pesquisa realizada.

Por último, 9\% estão aplicadas para design como aparência de produto. No exemplo da figura 6, a propaganda de uma empresa de mármores e granitos apresenta, em seu cartão de visita, vários adjetivos para promover o seu trabalho e design, aqui, é empregado para conotar estilo e aparência. Tal fato também é explicado por Landim (2008), que destaca que o público tem grande dificuldade em compreender a prática do design e o entende somente superficialmente, especificamente rementendo o design apenas a beleza e a comunicação comercial. Esse apossamento da palavra design como estilo e aparência veio com a busca da diferenciação no mercado competitivo. Bonsiepe (2012) constata essa questão ao afirmar que o público frequentemente compreende o design de modo superficial, que acaba sendo amplamente vinculado apenas aos valores estéticos-formais.

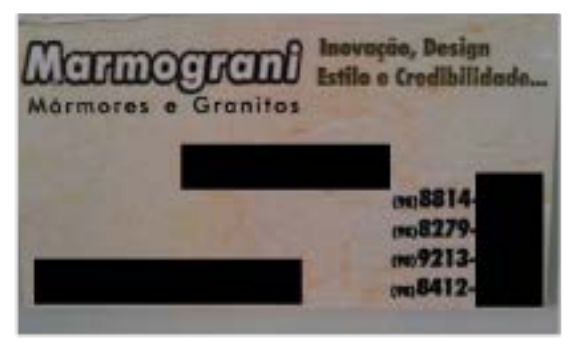

Figura 6: Cartão de visita da empresa Marmograni com uso da palavra design classificada como aparência de produto.

Elaborado pelos autores, com base na pesquisa realizada.

Durante a análise das fotos, percebeu-se que há uma falta de conhecimento da palavra "design" em São Luís, em que encontramos seus usos e aplicações errôneas e inadequadas, distribuídas em diversos contextos como em aparência, nomes de empreendimentos e atividade profissional. Na figura 7, nota-se a falta de discernimento entre a palavra Design e Designer, enquanto a primeira indica conceito, projeto, processo, curso, entre outros a segunda é utilizada especificamente para 
profissionais da área, o que faz o Design (FASCIONI, 2014). No caso da figura 7, a intenção do proprietário era utilizar a palavra como nome do empreendimento, tentando indicar a área que ele trabalha.

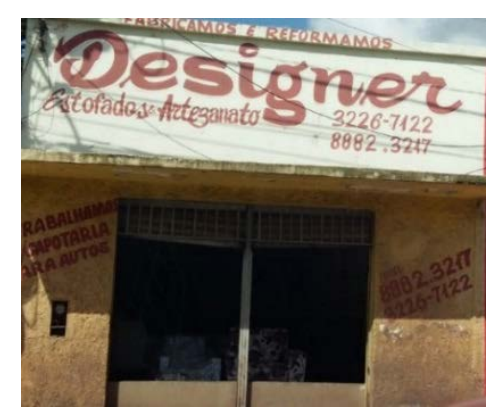

Figura 7: Loja de estofados e "artezanato".

Elaborado pelos autores, com base na pesquisa realizada.

Outros exemplos, encontram-se na figura 8, portanto nestes casos, a palavra "designer" foi utilizada de forma errônea, quando o intuito seria indicar um serviço.

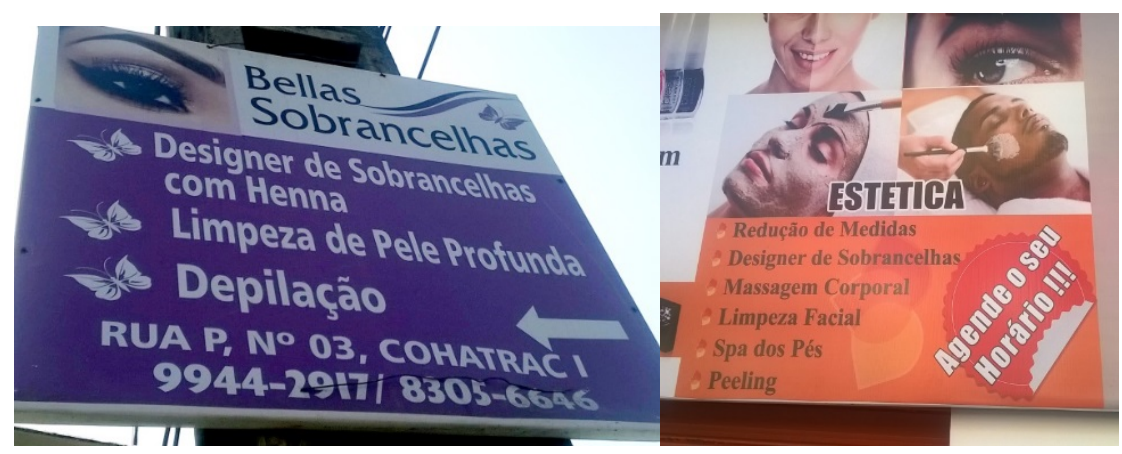

Figura 8: Serviços de design de sobrancelhas indicados em banners.

Elaborado pelos autores, com base na pesquisa realizada.

Para último exemplo, a figura 9 demonstra o uso da palavra como aparência, onde a manicure tenta comunicar o estilo do seu serviço que é de esmaltação simples, sem aplicação de desenhos e decorações. Observa-se novamente a associação popular do termo "design" como valor estético. Além disso, mais uma vez, têm-se a troca de "design" com "designer" (o profissional).

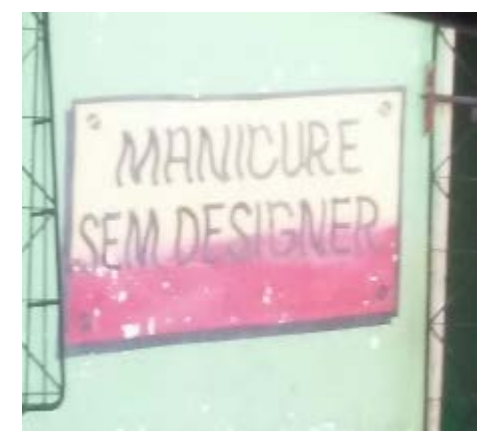

Figura 9: Comunicado e detalhamento de um serviço que não contem design em sua aplicação. Elaborado pelos autores, com base na pesquisa realizada. 


\section{CONSIDERAÇÕES FINAIS}

Foi possível observar que o emprego equivocado do termo "design" permeia tanto em bairros de altos rendimentos mensais, assim como nos baixos, desvinculando assim a correlação da palavra design dos padrões dos níveis de suas localidades. Através dos resultados obtidos, constatou-se que o uso da palavra "design" está amplamente associado com a estética, assim como é uma forma de agregar valor nas atividades comerciais, seja na denominação de empreendimentos, ou na utilização como um "adjetivo" de qualidade em seus serviços, sem contar com a sua utilização para promover outras áreas comerciais, tais como "design de sobrancelhas", "bolos" e "convites". Ou seja, o Design é visto como uma vantagem competitiva no comércio, consequência talvez de sua grande exposição na mídia nos últimos anos, portanto, o seu entendimento pode continuar vago e superficial para grande parte do público. Em São Luís, para novos resultados em pesquisas futuras, devemos aprofundar essas relações e entender como eles conheceram este termo, se foi somente através da publicidade, ou se realmente eles tiverem algum direcionamento técnico para um assunto específico, tal como existe para design gráfico, web design e até design de sobrancelhas. Além de buscar compreender o porquê de o utilizarem como uma forma de promover em seus trabalhos. Há outros motivos além da publicidade ou da estética? Eles se enxergam como um profissional da área de design? Entendem parcialmente ou possuem o conhecimento do todo, design como projeto, plano, resolução de problema entre outros conceitos?

\section{REFERÊNCIAS}

AZEVEDO, Wilton. O que é Design. São Paulo. Ed. Brasiliense, 1998.

BONFIM, G. Gustavo Amarante Bomfim: Uma coletânea. Rio de Janeiro: Rio Book's 1o Edição, 2014.

BONSIEPE, G. Design como prática de projeto. São Paulo. Blucher, 2012.

CARDOSO, R. Design para um mundo complexo. São Paulo: Cosac Naify, 2013.

DENIS, R. C. Uma Introdução à História do Design. São Paulo: Edgard Blücher, 2000.

Dicionário eletrônico Houaiss de Língua Portuguesa. Editora Objetiva: 2009.

Dicionário Escolar Latino-Português. 3 ed. FARIA, E. (Org.) Campanha nacional de material de ensino, 1962.

DOMINGUES, F. Design e cultura em produtos globais: A semiótica como ponto de convergência. São Paulo. Blucher acadêmico, 2011

Espírito Santo, José Marcelo (Org). São Luís: uma leitura da cidade. Prefeitura de São Luís / Instituto de Pesquisas e Planificação da cidade. São Luís: Instituto da Cidade, 2006.

FASCIONI, L. Indicadores para avaliação da imagem corporativa das empresas de base tecnológica instaladas na grande Florianópolis baseados nas análises das percepções gráfica e verbal utilizando lógica difusa. Florianópolis, 2003, Tese (Doutorado) Programa de Pós-graduação em Engenharia de Produção, Universidade Federal de Santa Catarina. 
FASCIONI, L. O design do designer. 2o Edição, 2014.

GODOY, L.; EVANGELISTA, M.; PIZZOLATO, M.; FERREIRA, A. A UTILIZAÇÃO DO DESIGN COMO VANTAGEM COMPETITIVA NO SETOR MOVELEIRO DE SANTA MARIA/RS.

Revista Científica Eletrônica de Engenharia de Produção. Florianópolis, SC, 2012.

LANDIM, P. C. Design, Empresa, Sociedade. São Paulo. UNESP. 2010.

LOBACH, B. Design Industrial - Bases para configuração dos produtos Industriais. São Paulo. Blucher, 2001.

MOURA, M. $O$ design de hipermídia. 2003. Tese (Doutorado) - Pontifícia Universidade Católica de São Paulo. Programa de Pós-Graduação em Comunicação e Semiótica.

O DESIGN NO BRASIL - RELATÓRIO 2014. 2016. Disponível em:

<http://www.sebrae.com.br/sites/PortalSebrae/artigos/o-design-no-brasil-relatorio2014,6d818242d5e67410VgnVCM1000003b74010aRCRD> Acesso em: 20 de maio de 2016.

PRODANOV, C., FREITAS, E. Metodologia do Trabalho científico: métodos e técnicas da pesquisa e do Trabalho acadêmico. Novo Hamburgo: Feevale. 2013. 2a ed.

VAN DER LINDEN, J. C. S.; POSSATTI, G. M.; PIERRE DA SILVA, R. Reflexões sobre as relações entre design e complexidade. 11 P\&D Design, Congresso Brasileiro de Pesquisa e Desenvolvimento em Design. Gramado, 2014. 